\title{
SERVIÇO MULTI-CANAL: UMA ESTRATÉGIA PARA O FUTURO
}

\author{
João Carlos Gonçalves dos Reis ${ }^{*}$, Nuno Filipe Rosa Melão ${ }^{* *}$
}

\begin{abstract}
Resumo: Desde o seu aparecimento, os serviços têm assumido um papel vital nas nossas vidas. Recentemente, com o despoletar das novas tecnologias e com a difusão da Internet, os serviços multicanal obtiveram uma atenção considerável no relacionamento entre clientes e organizações. Este artigo fornece uma síntese de literatura sobre os serviços multicanal, com especial destaque para as suas vantagens e limitações e para as questões de qualidade. Conclui-se que em geral os benefícios ultrapassam as suas limitações e que as questões de qualidade estão inerentemente ligadas ao desenho e controlo de serviços multicanal. Este artigo é também um convite para investigação adicional nesta área.
\end{abstract}

Palavras-Chave: Serviços, operações, Internet, serviços multicanal, qualidade.

\begin{abstract}
Abstratct: Since their emergence, services have taken a vital role in our lives. Recently, with the appearance of new technologies and the diffusion of the Internet, multichannel services received a considerable attention in the relationship between customers and organizations. This article provides a synthesis of the literature about multi-channel services, with special emphasis on its advantages and limitations and on quality issues. It is concluded that in general the benefits outweigh its limitations and that quality issues and inherently linked to the design and control of multi-channel services. This paper is also a call for further research in this area.
\end{abstract}

Key words: Services, operations, Internet, multi-channel services, quality.

\footnotetext{
* Mestre em Gestão de Negócios, Centro Regional das Beiras, Universidade Católica Portuguesa.

${ }^{* *}$ Docente do Centro Regional das Beiras, Universidade Católica Portuguesa. E-mail: nmelao@crb.ucp.pt
} 


\section{INTRODUÇÃO}

Os serviços só têm sido reconhecidos desde os anos 70 e 80 como sendo diferentes dos produtos porque a produção e o consumo são geralmente efectuados em simultâneo, o que raramente acontece com os bens (Johnston, 1999). O aparecimento da Internet e a sua combinação com os serviços tradicionais, permitiu que se fossem manifestando novas formas de relacionamento entre os clientes e as organizações. Embora algumas organizações ainda continuem a desenvolver estruturas de serviço que funcionam só através da Internet (ex.: bancos virtuais) ou na forma tradicional (ex.: lojas), a evidência empírica sugere que, salvo em algumas situações, as estruturas híbridas conduzem em geral a uma posição competitiva mais sustentável (Porter, 2001). Por isso, este artigo, dá especial ênfase aos serviços multicanal, sendo aqueles que são entregues através de múltiplos canais (físicos e/ou virtuais).

Tal como acontece com qualquer nova área de conhecimento, os serviços multicanal suscitam vários desafios de investigação interessantes. O estudo das suas especificidades (ex., Coelho et al., 2003; Easingwood \& Storey, 1996), o desenvolvimento de abordagens para auxiliar a sua concepção, gestão e controlo (ex., Simons \& Bouwman, 2005; Sousa \& Amorim, 2009), e o estudo das questões inerentes à qualidade destes serviços (ex., Sousa \& Voss, 2006) são apenas alguns exemplos de temas que têm merecido a atenção dos investigadores. Mas pese embora o interesse crescente pelos serviços multicanal, esta área encontra-se ainda numa fase embrionária, carecendo de mais estudos científicos.

Este artigo procura fazer uma síntese do estado da arte dos serviços multicanal. A primeira secção centra a atenção nos serviços tradicionais, identificando as suas características e discutindo as várias perspectivas de qualidade a elas associadas. A secção seguinte apresenta uma análise dos conceitos de serviços multicanal, dos seus benefícios e desvantagens e das suas componentes de qualidade. A secção final sugere algumas áreas de investigação futura. Apesar de não constituir uma revisão exaustiva das questões associadas aos serviços multicanal, espera-se que este artigo lance as bases para uma reflexão profunda que contribua para estimular futuras investigações na área.

\section{OS SERVIÇOS TRADICIONAIS}

Nesta secção, numa primeira fase, analisamos as características fundamentais dos serviços tradicionais; numa segunda fase, avaliámos questões relacionadas com a qualidade do serviço, nomeadamente, a qualidade percebida, as cinco dimensões essenciais que determinam a qualidade dos serviços e outras perspectivas de diversos investigadores da área. 


\subsection{Características dos serviços}

Grönroos (2001) refere-se aos serviços como um "fenómeno complicado", pela difícil distinção entre bens e serviços. A característica mais importante dos serviços será o facto de serem processos e não "coisas". Normalmente o consumo e a produção dos serviços são actividades parcialmente simultâneas, porque muitas vezes os clientes participam no processo de produção, tornando-se co-produtores. Tudo indica que uma organização que preste serviços não tem produtos, apenas processos interactivos. Grönroos (2001) identifica quatro características gerais e que podem ser observadas na maioria dos serviços: intangibilidade; oportunidade; simultaneidade; consumidor como co-produtor.

Cox \& Dale (2001) afirmam, muito à semelhança dos autores já referidos, que os serviços são caracterizados essencialmente por ser intangíveis, simultâneos e heterogéneos; uma vez perdidos não podem ser consumidos novamente ou no futuro. Da análise da literatura (Parasuraman et al., 1985; Leyland et al., 1999; Johnston \& Clark, 2001; Heizer \& Render, 2001; Grönroos, 2001; Fitzsimmons \& Fitzsimmons, 2008) podemos inferir que os serviços possuem as seguintes características fundamentais, sendo as mais importantes:

- Participação dos clientes no processo: a participação dos clientes no processo é fundamental para o aumento da performance do serviço; enquanto a experiência, o feedback e a honestidade dos clientes são factores essenciais para o desenvolvimento do processo;

- Simultaneidade: os serviços normalmente são produzidos e consumidos simultaneamente, não podendo ser aproveitados fora do tempo de execução;

- Oportunidade: os serviços normalmente são uma oportunidade, dada a impossibilidade de muitos deles se repetirem. Uma vez extintos ou consumidos não podem ser reutilizados;

- Intangibilidade: os serviços ao contrário dos bens não são algo de palpável; são ideias, performances ou experiências, enquanto os produtos são coisas;

- Heterogeneidade: subentende-se heterogeneidade como ligação entre cliente e a entrega do serviço (muitas vezes interpessoal). A relação entre consumidor e colaborador é fulcral para o sucesso das organizações na realização de um serviço de qualidade.

Os serviços podem ainda ser divididos, de acordo com Sousa \& Voss (2006), na perspectiva dos serviços através da Internet:

- Serviço Virtual: componente de informação pura, correspondente à experiência do serviço prestado ao consumidor, de forma automatizada (sem intervenção humana), através de um determinado canal virtual (ex., multibanco, dispositivos móveis); 
- Serviço Físico: corresponde à porção da experiência do consumidor em relação ao serviço, de forma não-automatizada (requerendo algum grau de intervenção humana).

\subsection{Qualidade dos serviços}

Explicar a qualidade tem sido uma tarefa difícil para os investigadores. Apesar de ser algo ainda um pouco ambíguo, a sua importância para as organizações e para os clientes é indiscutível. Garvin (1984) vai de encontro com esta linha de pensamento e identifica a qualidade como sendo algo de complexo e multifacetado. Apesar do crescimento fenomenal dos serviços, os investigadores têm-se debruçado nesta área para os conseguir compreender. A qualidade do serviço (QS), segundo Grönroos (2001), é distinguida em "qualidade técnica" (o quê é entregue - o what) e "qualidade funcional" (como o serviço deve ser entregue - o how). Tal permite caracterizar a concepção do serviço, ao fornecer uma ideia de como um serviço deve ser prestado com qualidade e quais os resultados que os clientes devem esperar. Gummesson (1988) afirma que todas as organizações devem produzir/ vender bens e serviços, gerindo a qualidade e as sinergias entre si. Contudo, a maioria dos investigadores revela que é extremamente difícil definir a qualidade por poucas palavras (Garvin, 1984; Sousa \& Voss, 2002).

Portanto, como já foi referido, a QS pode ser segundo Grönroos (2001), agrupada em qualidade técnica (qualidade do output) e qualidade funcional (qualidade do processo):

- A primeira dimensão corresponde aos itens de qualidade associados ao serviço que o cliente recebe.

- A segunda dimensão é o resultado da entrega do serviço. Esta avaliação da qualidade é influenciada não só pela imagem que o cliente tem relativamente ao prestador antes de o serviço ser fornecido, como também após a sua prestação.

A imagem que o consumidor possui da entidade prestadora do serviço influencia a sua percepção de qualidade no momento em que o serviço é prestado. Por isso, Grönroos (1982) sugere que a imagem possa ter uma influência decisiva na percepção da qualidade que os clientes têm para com a prestação do serviço. Nesta linha de pensamento, o autor apresenta o modelo da qualidade percebida (Figura 1). 
Figura 1

Qualidade percebida do serviço (Grönroos, 1988)

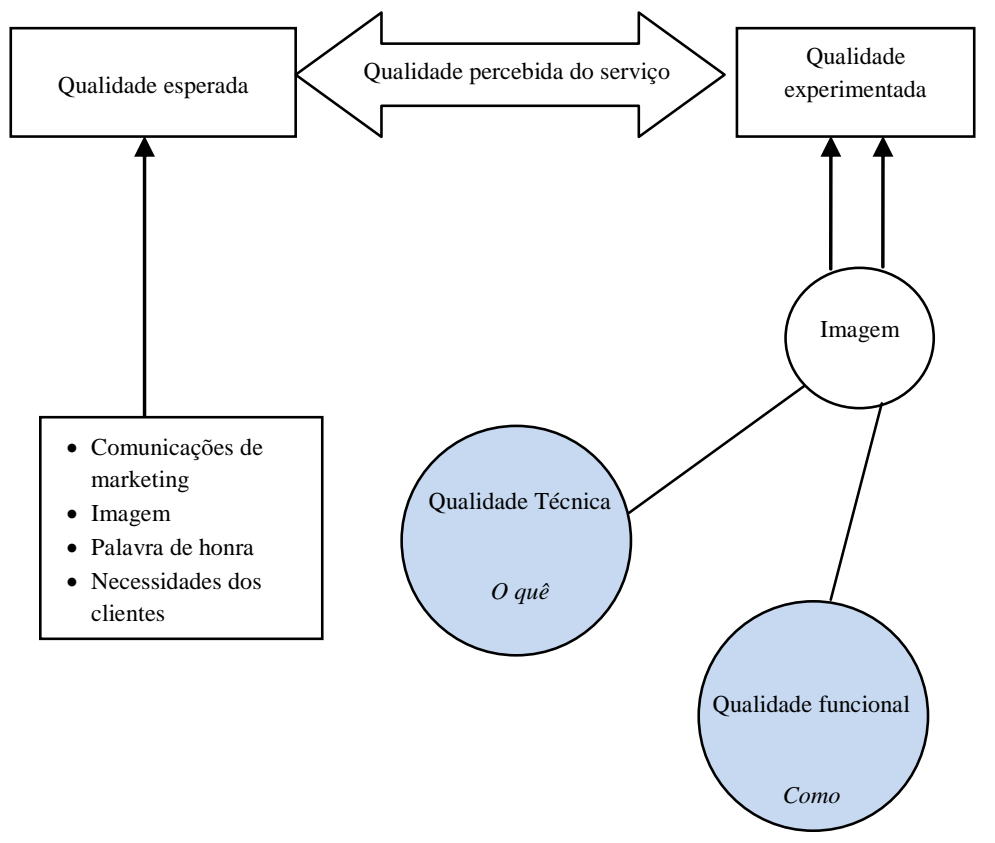

A qualidade percebida advém, assim, da relação directa entre as expectativas que os clientes têm em relação à QS e a experiência que têm com a organização quando esta lhes presta o serviço (relação com qualidade técnica e funcional). Parasuraman et al. (1988) e Berry et al. (1990) afirmam, à semelhança de Grönroos (1988), que a QS é feita entre a comparação de expectativas e performances. Esta interpretação de QS, percebida pelos clientes, é recebida pela comparação entre o que eles julgam da QS (expectativas) com as performances e desempenho da organização (quanto ao fornecimento do serviço). A qualidade percebida é, portanto, vista como a discrepância entre as percepções e as expectativas (P-E) dos clientes (Parasuraman et al., 1988).

\subsubsection{Avaliação da qualidade do serviço}

Embora a QS remonte há sensivelmente duas décadas atrás (Zeithaml et al., 2002), a sua avaliação também tem apresentado dificuldades. Contudo, existe algum consenso, na medida em que a QS pode ser determinada através das expectativas e percepção de qualidade nos clientes em relação à performance da organização (Berry et al., 1990), mas a sua medição é difícil! 


\section{Quadro 1}

\begin{tabular}{cl} 
As cinco dimensões da qualidade do serviço (Parasuraman et al., 1988) \\
\hline Tangibilidade & $\begin{array}{l}\text { A aparência das instalações, equipamento, pessoal e material de } \\
\text { comunicações. }\end{array}$ \\
\hline Fiabilidade & $\begin{array}{l}\text { A capacidade de fornecer o serviço ao qual se comprometeu de forma } \\
\text { digna e cuidada. }\end{array}$ \\
\hline Empatia & O cuidado e atenção individualizada que é prestado aos clientes. \\
\hline Capacidade de resposta & $\begin{array}{l}\text { A vontade de ajudar os clientes e de proporcionar um serviço de } \\
\text { qualidade. }\end{array}$ \\
\hline Confiança & $\begin{array}{l}\text { O conhecimento e cortesia dos colaboradores e a sua capacidade de } \\
\text { consagrar confiança e segurança aos clientes. }\end{array}$ \\
\hline
\end{tabular}

Parasuraman et al. (1988) apresentam um estudo sobre as expectativas dos clientes e identificam 10 dimensões que influenciam a percepção da QS. Posteriormente, as dimensões foram utilizadas como instrumentos de medida numa escala - SERVQUAL. Com o evoluir deste modelo, foram identificadas cinco dimensões essenciais para determinar a qualidade nos serviços tradicionais (Quadro 1).

Enquanto os clientes podem apreciar a qualidade em termos da sua funcionalidade e dos seus standards, encontram dificuldades em medir a QS. Esta dificuldade existe porque os clientes têm que avaliar não só o serviço mas, também, o processo de entrega. Desta forma, antes de um consumidor requisitar um serviço, este tem expectativas em relação à prestação deste, baseado nas suas necessidades individuais, experiências passadas, recomendações e comunicações de marketing do provedor do serviço para formular a sua ideia (Parasuraman et al., 1988).

\subsubsection{Outras perspectivas da qualidade do serviço}

Sabemos que a qualidade é essencial quando o serviço é o que está a ser prestado (Berry et al., 1985). Tanto Berry et al. (1985) como Parasuraman et al. (1988) procuram compreender a natureza e os determinantes da QS. Berry et al. (1985) identifica quatro conclusões importantes acerca da concepção da QS:

- As percepções dos clientes da QS resultam da comparação das expectativas antes de receberem o serviço e a actual experiência com o serviço. Estas conclusões são muito similares às efectuadas por Grönroos e já estudadas anteriormente. Se as expectativas forem verificadas, a qualidade esperada do serviço é satisfatória; se não forem verificadas a QS é menos que satisfatória; se forem excedidas é mais que satisfatório.

- A avaliação da qualidade deriva do processo (do serviço), ou seja, das relações interpessoais entre prestador do serviço e clientes. A forma de como o serviço é prestado pode ser crucial do ponto de vista do consumidor. Esta avaliação é muito idêntica à de Teas (1993), que 
considera a QS proveniente da experiência que o cliente tem com a organização. A qualidade verifica-se quando as necessidades dos clientes são plenamente respondidas.

- A QS é entendida de duas formas: em primeiro lugar, existe o nível de qualidade onde o serviço regular é entregue; em segundo lugar, existem os níveis de qualidade onde se inserem as expectativas e a resolução de problemas.

- Quando os problemas acontecem, o contacto entre a empresa e o cliente que é, regra geral, reduzido, torna-se num grande contacto entre a empresa e o cliente. Por exemplo, na banca quando o consumidor utiliza o cartão de crédito tem pouco contacto com o Banco, mas quando surge um problema esse contacto torna-se mais pessoal com a organização.

Berry et al. (1985) acaba por classificar o desafio da QS ao afirmar que isto se pode conseguir quando as necessidades e as perspectivas dos clientes são superadas (Figura 2).

Figura 2

A continuidade do serviço da qualidade percebida (Berry et al., 1985)

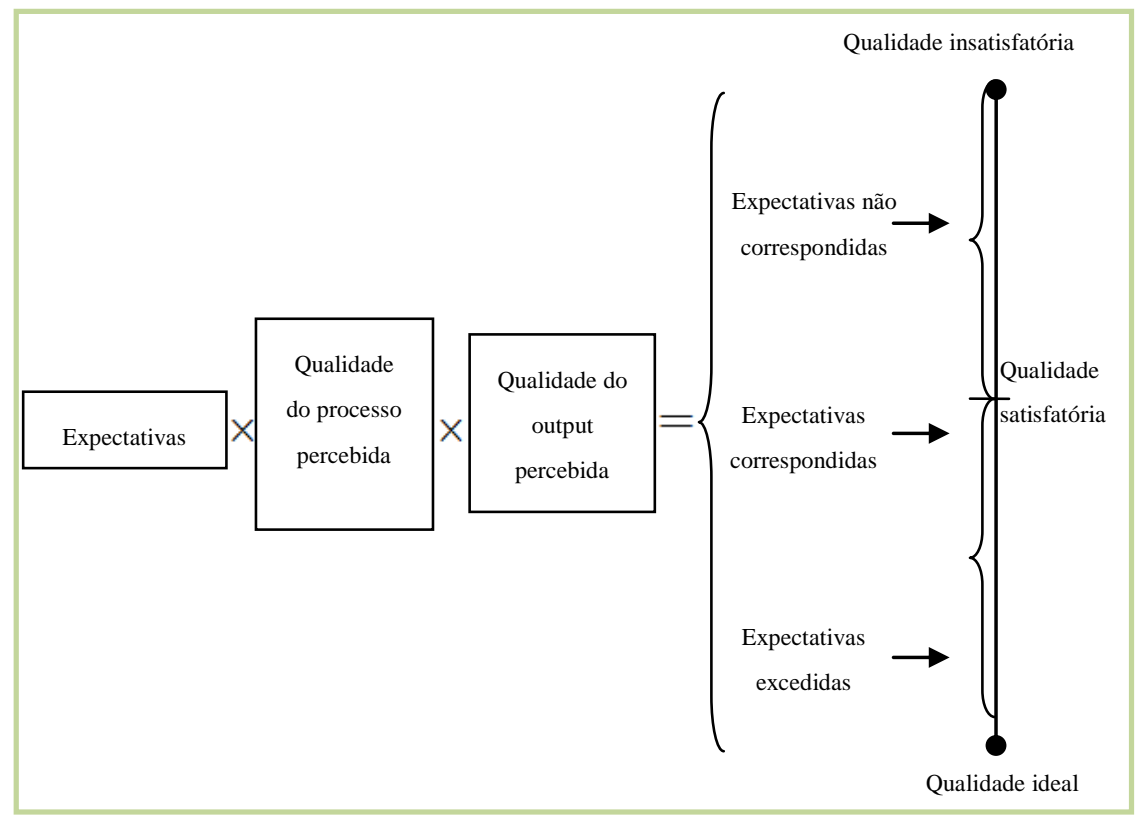

Johnston (1992) afirma que as organizações internacionais de sucesso baseiam o seu sistema de gestão na vontade dos seus clientes, utilizando o TQM (Total Quality Management - gestão da qualidade total) como estratégia de 
gestão. Esta filosofia requer que a organização alinhe as suas estruturas e os seus processos - produto ou desenho do serviço, marketing e vendas, relações com o consumidor e serviço pós-venda - à satisfação total do consumidor. Menciona ainda que o TQM vai para além das iniciativas de qualidade praticadas de forma dividida dentro das organizações, acabando por abranger toda a organização, desde o processo de produção até ao consumidor final, o que influencia determinantemente a QS. Por fim, Johnston (2004) tenta fazer uma aproximação à definição de "excelência do serviço", concluindo que é insuficiente definir excelência do serviço como a superação das expectativas dos clientes. Em última instância, inferiu que a proposta para a excelência poderia estar relacionada com as expectativas, mas requer que as organizações façam aquilo que prometem e se as coisas correrem mal, que exista um bom sistema que saiba dar respostas.

Juran (1986) vê a QS de acordo com cinco dimensões diferentes: qualidade interna (qualidade não visível aos clientes); qualidade do hardware (qualidade tangível, visível ao consumidor); qualidade do software (ex., qualidade intangível, qualidade da informação); tempo de entrega (tempo de entrega do serviço); e a qualidade psicológica (atitude do prestador de serviço perante o consumidor).

Gummesson (1993) fala-nos do modelo dos 4 Q's, isto é, o modelo dos quatro tipos de factores que estão ligados à qualidade, nomeadamente, o design, a qualidade técnica, a qualidade de produção e da distribuição, e a qualidade relacional (QS: em conformidade com o relacionamento do prestador de serviço e o cliente). O ponto de vista do autor está relacionado com a ideia de qualidade de acordo com as expectativas, experiências e a imagem ou marca de um determinado serviço.

Cronin \& Taylor (1992) investigaram a conceptualização e medida da QS, mas também a sua relação com a satisfação dos clientes. Eles apresentam literatura e dados empíricos que suportam a sugestão de que a QS deve ser medida como uma atitude e desenvolvida através de uma escala chamada SERVPERF (Cronin \& Taylor, 1994). Como resultado, a QS é um antecedente da satisfação dos clientes.

Teas (1993) defende que a QS tem recebido maior atenção na diferença entre as percepções e as expectativas (P-E), tal como descrito por Parasuraman et al. (1985). Parasuraman et al. (1988) define percepções como as crenças dos clientes na entrega do serviço e expectativas como sendo um termo vago da relação com a entrega do serviço ou uma ideia geral da performance. $\mathrm{O}$ modelo do desempenho de Teas (1993) difere em parte do modelo de Parasuraman ao considerar que a avaliação da QS está relacionada com a satisfação que os clientes têm com os serviços e com as intenções de recompra ou de nova utilização desses serviços. Teas (1993) considera que a QS provém da experiência que o cliente tem com a organização, onde os atributos idealizados pelo cliente são plenamente correspondidos. Sendo assim, a organização deverá 
examinar todos os atributos da qualidade que são percepcionados pelos clientes (qualidade percebida) para atingir elevados padrões de qualidade. O Quadro 2 sumaria a discussão.

\section{Quadro 2}

Síntese da literatura referente aos modelos de qualidade nos serviços.

\begin{tabular}{|c|c|c|c|}
\hline Autor & Modelo & Características & Área de estudo \\
\hline $\begin{array}{l}\text { Berry et al. } \\
\quad(1985)\end{array}$ & $\begin{array}{l}\text { Relação entre a qualidade e } \\
\text { serviço. }\end{array}$ & $\begin{array}{l}\text { Faz uma análise onde inclui } 10 \\
\text { determinantes de qualidade, chegando a } \\
\text { quatro conclusões importantes entre a } \\
\text { relação dos clientes com o prestador de } \\
\text { serviço. }\end{array}$ & $\begin{array}{l}\text { Vários tipos de } \\
\text { serviços (análise em } \\
4 \text { sectores distintos } \\
\text { de serviços) }\end{array}$ \\
\hline $\begin{array}{l}\text { Grönroos } \\
\text { (1988) }\end{array}$ & $\begin{array}{l}\text { Modelo da qualidade } \\
\text { percebida do serviço }\end{array}$ & $\begin{array}{l}\text { Compara modelos de marketing } \\
\text { tradicional com marketing dos serviços, } \\
\text { pelo que serviços são processos e não } \\
\text { coisas. As empresas não têm produtos, } \\
\text { apenas processos interactivos. }\end{array}$ & $\begin{array}{l}\text { Vários tipos } \\
\text { serviços }\end{array}$ \\
\hline $\begin{array}{l}\text { Gummesson } \\
\text { (1993) }\end{array}$ & Modelo 4Q’s & $\begin{array}{l}\text { Serviços e bens são parte do serviço } \\
\text { final. A qualidade percebida provém das } \\
\text { expectativas, experiência, e da marca ou } \\
\text { imagem de um determinado produto }\end{array}$ & $\mathrm{N} / \mathrm{A}$ \\
\hline $\begin{array}{c}\text { Juran } \\
(1986)\end{array}$ & Planeamento estratégico & $\begin{array}{l}\text { Coloca a qualidade como uma } \\
\text { necessidade estratégica das organizações }\end{array}$ & N/A \\
\hline $\begin{array}{l}\text { Cronin \& } \\
\text { Taylor } \\
(1994)\end{array}$ & $\begin{array}{l}\text { SERVPERF (instrumento } \\
\text { de medida da qualidade dos } \\
\text { serviços) }\end{array}$ & $\begin{array}{l}\text { A qualidade é vista como a atitude que os } \\
\text { clientes transmitem em relação às } \\
\text { dimensões de qualidade. }\end{array}$ & $\begin{array}{l}\text { Maior ênfase na } \\
\text { banca }\end{array}$ \\
\hline $\begin{array}{l}\text { Zeithaml et } \\
\text { al. (2002) }\end{array}$ & $\begin{array}{l}\text { SERVQUAL (instrumento } \\
\text { de medida da qualidade dos } \\
\text { serviços) }\end{array}$ & $\begin{array}{l}\text { A qualidade depende de uma escala de } \\
22 \text { itens e } 5 \text { dimensões. A qualidade está } \\
\text { relacionada com a diferença entre as } \\
\text { expectativas e o desempenho (E-D). }\end{array}$ & $\begin{array}{l}\text { Vários sectores de } \\
\text { serviços }\end{array}$ \\
\hline Teas (1993) & $\begin{array}{l}\text { Avaliação da Performance } \\
\text { (percepções - expectativas) }\end{array}$ & $\begin{array}{l}\text { Os atributos do serviço percepcionados } \\
\text { pelos clientes influenciam os parâmetros } \\
\text { da qualidade percebida. }\end{array}$ & $\mathrm{N} / \mathrm{A}$ \\
\hline
\end{tabular}

\section{SERVIÇO MULTI-CANAL}

Para definir os serviços multicanal consideramos fundamental discutir quatro elementos: em primeiro lugar, o conceito de canal de serviço e os tipos de canais de serviço identificados na literatura; em segundo lugar, a definição de serviço multicanal; em terceiro lugar, os benefícios e desvantagens dos serviços multicanal; finalmente, a qualidade do serviço multicanal e os seus componentes. 


\subsection{Conceito de canal de serviço}

Os canais podem ser definidos como fracções das organizações que disponibilizam produtos ou serviços no mercado (Stern et al., 1996). Por sua vez, Neslin et al. (2006) faz uma aproximação muito semelhante quando refere que os canais são como pontos de contacto, local onde a organização e o cliente interagem.

Em suma, canal é o meio que suporta as interacções entre os clientes e o prestador de serviços (Neslin et al., 2006, Sousa \& Voss, 2006). Os canais têm características distintas em relação ao tipo de interface que utilizam e a natureza das suas interacções com os clientes, podendo ser (Froehle \& Roth, 2004; Coelho et al., 2003):

- Cara-a-cara: os clientes interagem directamente com os colaboradores da organização;

- Cara-ecrã: interacções entre clientes e a tecnologia existente.

\subsubsection{Tipos de canais de serviço}

Sousa \& Voss (2006) fazem referência ao canal de entrega do serviço, canal virtual e canal físico, por esta ordem:

- Canais de entrega do serviço: são os meios de comunicação, através do qual um serviço é entregue ao consumidor;

- Canal virtual: consiste nos meios de comunicação com o cliente, através do uso de avançadas plataformas de telecomunicações, informações e tecnologias multimédia;

- Canal físico: consiste nos meios de comunicação com o cliente, essencialmente através do uso de infra-estruturas físicas.

Segundo Sousa \& Amorim (2009), estes canais de prestação de serviço não devem competir entre si. Devem prestar respostas consistentes e devem dar oportunidades de escolha segundo o que é mais conveniente para os clientes.

\subsection{Definição de serviço multicanal}

Façamos primeiro uma alusão aos serviços multicanal.

Podemos imaginar, o que seria de nós passar por uma cidade movimentada, com um tráfico caótico, sem poucas ou nenhumas medidas coordenação, controlo e plataformas que harmonizassem todo o trânsito? Para isso existem actualmente, sinais de trânsito, semáforos, polícias, que orientam e normalizam toda esta afluência de condutores para um só ou vários locais de forma ordenada. O mesmo se passa com os clientes, que dada a procura pretendem afluir a um determinado local para obter determinados produtos ou serviços. Para garantir a 
QS, é necessário cada vez mais possuir canais ou plataformas que possam encaminhar os clientes a satisfazer as suas necessidades de forma ordenada.

As organizações modernas deparam-se com diversos problemas. Num mercado cada vez mais competitivo, vencer os desafios originados pelo ambiente externo tem sido uma das maiores dificuldades a superar. Estes desafios estão intimamente ligados com os clientes, porque são estes, que através dos negócios acrescem valor às organizações. Actualmente os canais virtuais são um dos meios mais comuns para estabelecer interacções entre organização e cliente. Esta ligação ocorre, especialmente, se os clientes estabelecerem a comunicação com os prestadores através de diversos canais.

Desde a segunda parte dos anos 90 o mundo conheceu o nascimento do comércio através da Internet. Este período foi caracterizado por inúmeras previsões acerca das alterações que ocorreram, nomeadamente nos serviços físicos (Simons \& Bouwman, 2006). Ainda durante o século XX alguns investigadores fizeram a previsão do aparecimento do consumo através de plataformas virtuais, nomeadamente Doody \& Davinson (1967), que anteciparam o que mais tarde viria a ser chamado de serviços electrónicos (Peterson et al., 1997).

É certo que os serviços virtuais são importantes na diferenciação dos serviços multicanal. Podemos observar que com o crescente uso da Internet, acompanhada pelo progresso tecnológico, têm-se vindo a evidenciar inúmeros benefícios para as organizações. Easingwood \& Storey (1996) referem que uma das origens dos serviços multicanal está associada à necessidade competitiva das organizações em expandir os seus mercados através de novos métodos. Uma segunda necessidade advém de muitas instituições financeiras se tornarem mais completas na prestação dos serviços, servindo os clientes com um rol alargado de produtos. Por último, afirma que a indústria reconhece que os seus canais tradicionais já não são suficientes para o cumprimento dos objectivos.

Concluindo, o serviço multicanal é composto por componentes físicos e/ou virtuais que são entregues através de vários canais, podendo também comprometer vários tipos de serviços (físicos e/ou virtuais) (Sousa \& Voss, 2006).

Mas os serviços multicanal também incorporam canais complementares e canais paralelos (Sousa \& Voss, 2006).

Os canais complementares são todos os canais que ao se complementar completam o serviço; podem-se verificar muitas vezes nos casos do comércio electrónico. Muitos canais virtuais disponibilizam a sua informação através da Internet. Os clientes podem escolher os seus produtos e porventura adquiri-los. Contudo, o suporte logístico deverá ser feito com recurso aos canais físicos - a esta complementaridade entre canais dá-se o nome de canais complementares.

Como alternativa ao caso anterior, os clientes podem decidir a combinação de canais com que se pretendem relacionar em cada serviço particular. Como no 
caso dos muitos sistemas financeiros (banca), os clientes destes sistemas podem optar tradicionalmente pelos serviços físicos para satisfazer as suas necessidades, ou pelos serviços virtuais e até multicanal.

\subsection{Benefícios e desvantagens dos serviços multicanal}

Actualmente a Internet ainda é predominantemente utilizada como canal de informação (Simons \& Bouwman, 2005). Contudo, algumas organizações, as mais evoluídas, têm sabido tomar partido das novas tecnologias, nomeadamente dos serviços electrónicos através de canais múltiplos. As empresas que terão sucesso serão aquelas que conseguem usar a Internet como complemento à sua forma tradicional de competirem (Sousa \& Voss, 2006). Muito à semelhança do autor anterior, Coelho et al. (2003) afirmam que as organizações podem escolher através de uma variedade alternativa de canais, podendo existir dois extremos: no caso da entrega dos serviços, uma organização efectua a distribuição da totalidade dos seus produtos (de forma tradicional), ou adopta uma estratégia com acesso a intermediários que executam a maior parte da distribuição de bens ou produtos. As estratégias de utilização de um só canal (uni-canal) são cada vez menos frequentes e torna-se cada vez mais regular a utilização de serviços multicanal.

Alguns factores têm vindo a fomentar a utilização dos sistemas multicanal, incluindo o aumento de vendas, maior cobertura de mercado e aumento da satisfação dos clientes (Thornton \& White, 2001). Com o aparecimento das novas tecnologias as organizações obtiveram uma redução dos custos, substituindo canais mais dispendiosos por canais mais económicos (Thornton \& White, 2001; Wright, 2002).

A fidelidade dos clientes tende a aumentar quando estes dispõem de um maior número de canais podendo fazer as suas escolhas e relacioná-los adequadamente entre si de forma a garantir um serviço mais completo e transparente. A lealdade dos clientes é crucial para a sobrevivência dos negócios, especialmente no contexto do comércio electrónico (Reichheld \& Schefter, 2000). Assim a experiência dos clientes através de canais múltiplos irá evocar a confiança destes, reforçando a sua relação com a organização (Simons \& Bouwman, 2006). Como resultado, os clientes utilizam tanto os canais virtuais como os tradicionais em seu complemento (Sousa, 2002a) e ao utilizar os mercados globais, através das vias electrónicas, as organizações vêem cada vez mais potenciada a sua capacidade competitiva. Contudo, recomenda-se que os canais não funcionem isoladamente; devem ser conduzidas estratégias que estabeleçam as relações entre os canais convencionais ou físicos (Peterson et al., 1997) e em simultâneo com os canais virtuais.

Birgelen et al. (2006) conciliou a componente tecnológica (Internet banking e o Mobile banking) às relações entre os clientes e os serviços físicos; quando 
ocorre esta união é permitido conjugar canais de duas naturezas distintas (físico e virtual). Neste estudo, também se verificou que os níveis de satisfação dos clientes aumentavam significativamente quando estes eram confrontados com a combinação dos serviços tradicionais e virtuais, o que consequentemente aumentava os níveis de QS. Os clientes têm dificuldade em aceitar um ou apenas dois canais. Actualmente sentem a necessidade de ter vários canais alternativos, como por exemplo, os e-mails, SMS, Web, Self-service, entre outros serviços mais tradicionais como é o exemplo dos balcões de atendimento, telefone, etc.

Resumindo, os serviços multicanal podem apresentar os seguintes benefícios:

- Aumento significativo das vendas. Coelho et al. (2003) refere-se ao aumento da cobertura de mercado, que representa a habilidade de aceder a segmentos de mercado que anteriormente não eram atingidos pela organização;

- Aumento da satisfação. A satisfação depende da escolha de canais que se encontram à disposição dos clientes. Dos canais individuais, o produto e a equidade do pagamento, são factores que influenciam a satisfação, tal como a consistência do sistema multicanal representa um grande impacto na satisfação dos clientes (Madaleno et al., 2007). Podemos verificar que a consistência entre canais de um sistema multicanal na interacção com os clientes pode resultar numa experiência de serviço uniforme (Sousa, 2002a). Simons \& Bouwman (2006) afirmam que a relação dos clientes com os vários canais pode resultar numa experiência positiva e evocar uma maior satisfação;

- Redução nos custos. Esta vantagem pode ser vista de várias perspectivas, dado que a existência de múltiplos canais pode oferecer aos utilizadores um acesso mais facilitado e barato. Contudo, esta adopção não é inteiramente livre de risco, pois o cliente pode-se sentir confundido devido à elevada variedade. Consequentemente, os custos podem aumentar e não diminuir dada a duplicação do esforço (Easingwood \& Storey, 1996);

- Maior e melhor informação. O uso integrado de canais permite às organizações melhorar as suas relações com os clientes e oferecer-lhes novas formas de interacção;

- Redução do risco do negócio. Uma organização que esteja dependente de um único canal, pode-se ver confrontada com as vulnerabilidades desta posição, nomeadamente na obtenção de respostas através desse canal (Coelho et al., 2003).

Contrariamente ao apresentado anteriormente encontramos muito poucas desvantagens, referentes à utilização dos serviços multicanal. Existe pois uma grande discrepância, entre o que foi identificado como vantagem e desvantagem, porém identificamos três aspectos passíveis de serem apresentados nesta seç̧ão. 
A existência de canais múltiplos pode produzir impactos negativos, como por exemplo a confusão nos clientes. Quando as ofertas chegam aos mercados com preços diferentes e diferentes níveis de serviço. Esta situação também pode originar conflitos entre canais.

O conflito entre canais ocorre por várias razões. Uma das mais importantes é proveniente das várias unidades, que ao competirem pelos mesmos clientes podem provocar conflitos. Esta situação é mais vincada quanto a organização não tem a capacidade de integrar os seus canais (Easingwood \& Coelho, 2003). Por isso, antevemos a necessidade das organizações apostarem cada vez mais na qualidade de integração. A interligação dos canais encoraja um comportamento desejável por parte dos clientes, um canal individual poderá implicar o uso de outro se estes estiverem interligados (Montoya et al., 2003). Desta forma entendemos que se as organizações conseguirem evitar a competição entre canais, a organização deixa de ter que lidar com um problema (desvantagem) e passa a ter uma vantagem competitiva sobre os seus concorrentes.

Por fim, a implementação de uma estrutura multicanal requer frequentemente a necessidade de um grande investimento (Coelho et al., 2003). Esse investimento normalmente é proveniente das necessidades tecnológicas, infraestruturas e de pessoal para alimentar o sistema multicanal.

\subsection{Qualidade dos serviços multicanal}

Como vimos, vários autores fazem diferentes aproximações à QS. Não deixando de esquecer os modelos apresentados, vamos debruçar-nos essencialmente nas diferentes dimensões apresentadas por Sousa \& Voss (2002). Esta abordagem refere-se à QS prestada tanto pela Internet como pelos serviços físicos.

\subsubsection{Componentes da qualidade do serviço multicanal}

Sousa (2002a) refere que a qualidade dos serviços multicanal compreende três componentes: a qualidade virtual, a qualidade física e a qualidade de integração.

Qualidade virtual é identificada como a qualidade do serviço prestado de forma automática, podendo ser fornecido com recurso à Internet, combinando ou não canais alternativos de prestação de serviço. A qualidade virtual teve maior ênfase com o aparecimento dos serviços electrónicos. Com o aparecimento das novas tecnologias associadas à oportunidade de negócio das organizações surgiram os serviços electrónicos (e-serviços). Estes e-serviços podem ser definidos como todos os serviços interactivos que são entregues na Internet/Web site, usando avançados sistemas de telecomunicações, informações e tecnologias multimédia onde se excluem interacções com os colaboradores da organização 
(Sousa, 2002b, p.2; Boyer et al., 2002). Por sua vez, alguns autores definem eserviços como os serviços produzidos pelos clientes interagindo através do Web site, excluindo qualquer interacção com os prestadores de serviço (Sousa \& Voss, 2006; Fassnacht \& Koese, 2006). Os serviços electrónicos são uma instância do serviço virtual, onde o canal virtual em questão é a Internet (Sousa \& Voss, 2006). A maioria dos e-serviços de sucesso são de natureza multicanal, ou seja, combinam em maior ou menor grau a Internet com canais alternativos de prestação de serviço (Sousa, 2002a).

\section{Quadro 3}

Componente virtual da qualidade (Sousa, 2002a; Bressolles \& Nantel, 2004)

\begin{tabular}{|c|c|c|}
\hline O que é? & e a qualidade do Web site, onde o se & ço e prestado o \\
\hline $\begin{array}{l}\text { Qualidade } \\
\text { Virtual } \\
\text { Compreende } \\
\text { as seguintes } \\
\text { dimensões: }\end{array}$ & $\begin{array}{l}\text { - Fulfillment virtual: Realização sem erros e } \\
\text { de acordo com o prometido da parte do } \\
\text { serviço automaticamente prestado pelo Web } \\
\text { site; } \\
\text { Facilidade de utilização: Facilidade de } \\
\text { navegação, operações intuitivas, organização } \\
\text { da informação; Rapidez no acesso e uso do } \\
\text { site. } \\
\text { Privacidade/segurança: O grau em que o site } \\
\text { é seguro e protege a informação dos clientes } \\
\text { Qualidade da informação: Qualidade do } \\
\text { conteúdo do site; a adequação da informação } \\
\text { aos objectivos do utilizador, por exemplo, a } \\
\text { exactidão, o formato e a relevância da } \\
\text { informação } \\
\text { Atracção visual: Estética, criatividade, } \\
\text { apresentação dos gráficos e texto do Web site. } \\
\text { (Sousa, 2002a) }\end{array}$ & $\begin{array}{l}\text { - Fiabilidade: Capacidade para } \\
\text { garantir os compromissos; } \\
\text { - Facilidade de uso: É referente } \\
\text { à facilidade percebida que o } \\
\text { cliente tem ao navegar num } \\
\text { determinado site; } \\
\text { - Segurança/ privacidade: } \\
\text { Segurança doa dados } \\
\text { financeiros e respeito pela vida } \\
\text { privada. } \\
\text { Informação: Quantidade e } \\
\text { qualidade de informação acerca } \\
\text { de um produto ou serviço; } \\
\text { Web design: Elementos } \\
\text { estéticos de um Web site; } \\
\text { (Bressolles \& Nantel, 2004) }\end{array}$ \\
\hline
\end{tabular}

A qualidade dos serviços electrónicos é vista aqui como fazendo parte da qualidade virtual. A este respeito, Sousa (2002a) identificou as dimensões que o Web site deverá possuir para fornecer um serviço de qualidade (ver Quadro 3): fulfillment virtual; facilidade de utilização, privacidade/segurança; qualidade da informação e atracção visual. Usualmente o fulfillment virtual é representado pela prestação do serviço através do Web site sem erros e de acordo com aquilo que foi estipulado. Associada a esta dimensão encontra-se a facilidade de utilização do Web site - os utilizadores para além de desejarem obter aquilo que foi acordado esperam poder navegar com alguma facilidade e rapidez. Cada vez mais a privacidade/segurança assume contornos relevantes, nomeadamente nas organizações bancárias, os clientes desejam ver as suas informações protegidas de qualquer intrusão. Para além disso, a qualidade da informação também é importante, na medida em que os clientes procuram a adequação da informação com aquilo que procuram no Web site. Por último, a qualidade virtual também é 
reflectida, não só na qualidade da informação que é disponibilizada, mas também pela atractividade do Web site, da estética, dos gráficos, entre outros aspectos.

\section{Quadro 4}

Medidas da qualidade do serviço online por investigador

\begin{tabular}{clcc}
\hline Instrumentos de medida & \multicolumn{1}{c}{ Descrição } & Autor \\
\hline WebQual 4 & $\begin{array}{l}\text { Composta por 22 itens em 3 dimensões (qualidade da } \\
\text { informação, interacção do serviço, navegação pelo } \\
\text { Web site) }\end{array}$ & $\begin{array}{c}\text { Barnes \& Vidgen } \\
\text { (2003) }\end{array}$ \\
\hline SiteQual & $\begin{array}{l}\text { Escala com 9 itens, distribuída em 4 dimensões } \\
\text { (Facilidade de utilização, design estético, velocidade } \\
\text { do processo e segurança) }\end{array}$ & Yoo \& Dontu (2001) \\
\hline EtailQ & $\begin{array}{l}\text { Escala com 14 itens, dividida em 4 dimensões } \\
\text { (design, serviço ao consumidor, fiabilidade e } \\
\text { segurança /privacidade) }\end{array}$ & Wolfinbarger \& \\
\hline E-S-Qual & $\begin{array}{l}\text { Escala de 22 itens, dividida em 4 dimensões } \\
\text { (eficiência, fulfillment, funcionalidade do sistema, } \\
\text { privacidade) }\end{array}$ & $\begin{array}{c}\text { Parasuraman } \text { et al. } \\
\text { (2005) }\end{array}$ \\
\hline
\end{tabular}

Para medir a qualidade do Web site foram também desenvolvidos alguns instrumentos de medição, como, por exemplo, o WebQual 4 (Barnes \& Vidgen, 2003), o SiteQual (Yoo \& Dontu, 2001), o EtailQ (Wolfinbarger \& Gilly, 2003) e o E-S-Qual (Parasuraman et al., 2005) (ver Quadro 4). Até à data não tem havido um consenso acerca das dimensões da qualidade nos serviços electrónicos. Contudo, as cinco dimensões apresentadas têm conseguido uma aceitação elevada. Como podemos observar no Quadro 3, nas dimensões identificadas por Sousa (2002a) e Bressolles \& Nantel (2004) não existem diferenças substanciais.

Resumindo, a qualidade virtual é muitas vezes identificada como a qualidade do Web site, onde o serviço é prestado de forma automatizada, sem esquecer que existem outros canais (alternativos) de prestação do serviço.

A qualidade física compreende a prestação do serviço através de canais físicos (telefone, correspondência, etc.), em complemento à Web. Inclui o apoio ao cliente e o serviço logístico (ver Quadro 5). 


\section{Quadro 5}

Componente física da qualidade (Lehtien \& Lehtien's, 1982; Sousa, 2002a)

\begin{tabular}{|c|c|}
\hline O que é? & Prestação do serviço através de meios físicos, em complemento à Web. \\
\hline \multirow[t]{2}{*}{$\begin{array}{c}\text { Qualidade } \\
\text { Física } \\
\text { Inclui: }\end{array}$} & $\begin{array}{l}\text { Apoio ao cliente: } \\
\text { Avaliado pelas dimensões Capacidade de Resposta, Compensação e Contacto. } \\
\text { - Capacidade de Resposta: Mede a capacidade de a organização disponibilizar } \\
\text { informação adequada quando surgem problemas e de ter mecanismos de devolução de } \\
\text { produtos e oferecer garantias online. } \\
\text { - Compensação: Envolve recuperar o dinheiro da compra, assim como os custos postais } \\
\text { da devolução física de produtos. } \\
\text { - Contacto: Envolve a capacidade de os clientes poderem falar com um agente humano de } \\
\text { apoio ao cliente. }\end{array}$ \\
\hline & $\begin{array}{l}\text { Serviço Logístico como background dos serviços virtuais: } \\
\text { Os serviços electrónicos que em última instância fornecem itens físicos para entrega: } \\
\text { - Disponibilidade do Inventário: Capacidade de fazer o sourcing do inventário } \\
\text { encomendado pelo cliente. } \\
\text { - Rapidez: Mede o tempo de ciclo e está inversamente relacionada com o tempo da } \\
\text { entrega a partir do inventário. } \\
\text { - Fiabilidade Logística: É uma medida global que captura a capacidade do prestador de } \\
\text { serviço em cumprir com as expectativas sinalizadas aos clientes em relação ao } \\
\text { desempenho do serviço de distribuição. } \\
\text { Serviço Logístico como background dos serviços físicos: } \\
\text { A principal diferença deste serviço em relação ao anterior relativo ao processo de entrega. }\end{array}$ \\
\hline
\end{tabular}

O apoio ao cliente tem como principal objectivo dar resposta ao cliente, mantê-lo satisfeito e informado. O serviço logístico faculta todos os itens físicos para entrega a pedido dos clientes, podendo ser (Sousa, 2002a, p.7):

- Serviço logístico como background dos serviços virtuais. Os serviços electrónicos, que em última instância fornecem itens físicos para entrega, recorrem a um vasto leque de opções para fazer o aprovisionamento desses itens e têm acesso a inventários que podem ser detidos internamente, ou por fornecedores externos. Como consequência, ao ser feito o processamento de encomendas, os prestadores de serviços têm que gerir o aprovisionamento, tirando vantagem do grande número de opções de armazenamento disponíveis;

- Serviço logístico como background dos serviços físicos. A principal diferença deste serviço em relação ao anterior está no processo de entrega. No caso das livrarias (que facultem um serviço físico e virtual) podem observar os seus clientes a efectuarem uma pesquisa e compra através da Internet, mas é necessário um serviço logístico por detrás para ir buscar o livro enviá-lo ao cliente. Contudo, o cliente pode ir directamente à livraria e ser atendido por um dos seus colaboradores que lhe entrega (através do serviço logístico) o livro requisitado, e é neste sentido que caracterizamos o serviço logístico como background dos serviços físicos. Sousa (2002a), 
à semelhança de Lehtien \& Lehtinen's (1982), reforça que a QS é produzida na interacção entre os clientes e os elementos da organização, ou seja, a qualidade física inclui os aspectos físicos do serviço tais como equipamentos ou instalações.

\section{Quadro 6}

Componente de integração da qualidade (Edwardsson et al., 1989; Sousa, 2002a)

\begin{tabular}{|c|c|}
\hline \multirow{3}{*}{$\begin{array}{c}\text { Qualidade } \\
\text { Integração } \\
\text { Compreende } \\
\text { as seguintes } \\
\text { dimensões: }\end{array}$} & $\begin{array}{l}\text { A capacidade de uma organização em prestar um serviço sem falhas (Edwardsson } \text { et al., } \\
\text { 1989) }\end{array}$ \\
\hline & $\begin{array}{l}\text { Configuração canais-serviço: } \\
\text { Refere-se à qualidade que existe entre a combinação disponível de serviços (ou componentes } \\
\text { de serviços) e canais associados. Compreende por sua vez duas sub-dimensões: } \\
\text { - Variedade de Escolha de Canais: Grau em que os clientes podem escolher canais } \\
\text { alternativos para um dado serviço e o grau em que os clientes podem realizar as tarefas } \\
\text { pretendidas através de cada canal disponível. } \\
\text { Transparência da Configuração: Grau em que os clientes têm conhecimento de todos } \\
\text { os canais existentes e das eventuais diferenças entre atributos do serviço (preços, } \\
\text { prazos de entrega, variedade de produtos/serviços) nos diferentes canais. }\end{array}$ \\
\hline & $\begin{array}{l}\text { Interacções Integradas: } \\
\text { Esta dimensão refere-se à consistência às interacções que os clientes experimentam através } \\
\text { de canais diferentes, resultando numa experiência de serviço uniforme. Compreende por sua } \\
\text { vez duas sub-dimensões: } \\
\text { - Consistência de Conteúdo: Refere-se à consistência entre a informação trocada com o } \\
\text { cliente através de diversos canais, incluindo informação de saída e de entrada. } \\
\text { - Consistência de Processo: Refere-se à consistência entre atributos de processo } \\
\text { relevantes e comparáveis (em relação às expectativas) dos front-office associados aos } \\
\text { diferentes canais. }\end{array}$ \\
\hline
\end{tabular}

A qualidade de integração refere-se à capacidade de uma organização em prestar um serviço sem falhas, compreendendo uma boa configuração canaisserviço e interacções integradas (Quadro 6). A configuração canais-serviço refere-se à qualidade que existe entre a combinação disponível de serviços (ou componentes de serviços) e canais associados. As interacções integradas referem-se à consistência das interacções que os clientes experimentam através de canais diferentes, resultando numa experiência de serviço uniforme (Sousa, 2002a, p.2). Edwardsson et al. (1989) também se refere à qualidade de integração, afirmando que os clientes devem ter uma experiência positiva tanto online como offline isto é, o Web Site (serviço virtual) deve estar interligado com o sistema de distribuição e entrega (serviço logístico). 


\section{CONCLUSÕES}

Em suma, e numa tentativa de sensibilizar alguns investigadores alertamos para a importância que os serviços multicanal têm para a qualidade dos serviços e para a satisfação dos clientes. Em última análise, verificamos que existe ainda algum vazio na literatura. Muito à custa do esforço de alguns investigadores assumimos ainda que têm sido efectuados alguns estudos de excelente qualidade científica. Contudo, devido à importância que estes serviços têm tido no nosso contexto social e económico julgamos ser necessária uma maior intervenção da comunidade académica. Propomos também a realização de trabalho de campo para compreender como se concebem, gerem e controlam este tipo de serviços. Muitas organizações têm feito um trabalho intenso para levar os serviços multicanal avante, não só por questões de competitividade, mas também porque sabem que este é o futuro dos serviços. 


\section{REFERÊNCIAS}

BARNES, S. e VIDGEN, R. (2003), "Measuring web site quality improvements: a case study of the forum on strategic management knowledge exchange", Industrial Management \& Data Systems, 103 (5), 297-309.

BERRY, L., ZEITHAML, V. e PARASURAMAN, A. (1985), "Quality Counts in Services, Too", Business Horizons, 28 (3), 44-52.

BERRY, L., ZEITHAML, V. e PARASURAMAN, A. (1990), "Five imperatives for improving service quality", Sloan Management Review, 31 (4), 29-38.

BIRGELEN, M., JONG, A. e RUYTER, K. (2006), "Multi-channel service retailing: The effects of channel performance satisfaction on behavioral intentions", Journal of Retailing, 82 (4), 367-377.

BOYER, K., HALLAWELL, R. e ROTH, A. (2002), "E-Services: Operating Strategy - A case study and a method for analyzing operational benefits", Journal of Operations Management, 20 (2), 175-88.

BRESSOLLES, G. e NANTEL, J. (2004), "Electronic service quality: A comparison of three measurement scales", In Proceedings of the 33th EMAC Conference, Murcia (Spain).

COELHO, F., EASINGWOOD, C. e COELHO, A. (2003), "Exploratory evidence of channel performance in single vs multiple channel strategies", International Journal of Retail \& Distribution Management, 31 (11/12), 561-573.

COX, J. e DALE, B. (2001), "Service quality and e-commerce: An exploratory analysis", Managing Service Quality, 11 (2), 121-131.

CRONIN, J. e TAYLOR, S. (1992), "Measuring service quality: A Reexamination and Extension", Journal of Marketing, 56 (3), 55.

CRONIN, J. e TAYLOR, S. (1994), "SERVPERF versus SERVQUAL: Reconciling Performance-Based and perceptions-minus-expectations measurement of service quality", Journal of Marketing, 58 (1), 125.

DOODY, A. e DAVIDSON, W. (1967), "Next revolution in retailing", Harvard Business Review, 45, 4-20.

EASINGWOOD, C. e COELHO, F. (2003), "Single versus multiple channel strategies: Typologies and drivers", The Service Industries Journal, 23 (2), 31-46.

EASINGWOOD, C. e STOREY, C. (1996), "The value of multi-channel distribution systems in the financial services sector", The Service Industries Journal, 16 (2), 223-241.

EDWARDSSON, B., GUSTAVSSON, B. e RIDDLE, D. (1989), An expanded model of the service encounter with emphasis on cultural context. Research 
Report, 89 (4), CTF Services Research Center, University of Karlstad, Sweden.

FASSNACHT, M. e KOESE, I. (2006), "Quality of electronic services Conceptualizing and testing a hierarchical model", Journal of Service Research, 9 (1), 19-37.

FITZSIMMONS, J. e FITZSIMMONS, M. (2008), Service Management: Operations, Strategy, Information Technology. McGraw-Hill.

FROEHLE, C. e ROTH, A. (2004), "New measurement scales for evaluating perceptions of technology-mediated customer service experience", Journal of Operations Management, 22 (1), 1-21.

GARVIN, D. (1984), "What does «Product quality» really means?", Sloan Management Review, 26 (1), 25.

GRÖNROOS, C. (1982), “An applied service marketing theory”, European Journal of Marketing, 16 (7), 30-45.

GRÖNROOS, C. (1988), "Service Quality: The six criteria of good perceived service", Review of Business, 9 (3), 10.

GRÖNROOS, C. (2001), "The perceived service quality concept - a mistake?", Managing Service Quality, 11 (3), 150-153.

GUMMESSON, E. (1988), "Service quality and product quality combined", Review of Business, 9 (3), 3.

GUMMESSON, E. (1993), Quality Management in service organizations. New York: ISQA (International service quality association).

HEIZER, J. e RENDER, B. (2001), Operations Management. Prentice Hall.

JOHNSTON, R. (1992), "Total quality management: Customer satisfaction guaranteed?", CMA Magazine, 66 (3), 15.

JOHNSTON, R. (1999), "Service operations management: return to roots", International Journal of Operations \& Production Management, 19 (2), 104-124.

JOHNSTON, R. (2004), "Towards a better understanding of service excellence", Managing Service Quality, 14 (2/3), 129.

JOHNSTON, R. e CLARK, B. (2001), Service Operations Management. London: FT Prentice Hall.

JURAN, J. (1986)," The quality trilogy", Quality Progress, 9 (8), 19-24.

LEHTINEN, J. e LEHTINEN, U. (1982), "Service quality: a study of quality dimensions", Service Management Institute, Helsinki, unpublished working paper.

LEYLAND, P., BERTHON, P. e WATSON, R. (1999), “Cyberservice: Taming service marketing problems with the World Wide Web", Business Horizons, 42 (1), 11-18. 
MADALENO, R., WILSON, H. e PALMER, R. (2007), "Determinants of customer satisfaction in a multi-channel B2B environment", Total Quality Management, 18 (8), 915-925.

MONTOYA, W., VOSS, G. e GREWAL, D. (2003), "Determinants of online channel use and overall satisfaction with a relational multichannel service provider", Journal of the Academy of Marketing Science, 31 (4), 448-58.

NESLIN, S., GREWAL, D., LEGHORN, R., SHANKAR, V., TEERLING, M., THOMAS, J. e VERHOEF, P. (2006), "Challenges and opportunities in multi-channel customer management", Journal of Service Research, 9 (2), 95-112.

PARASURAMAN, A., ZEITHAML, V. e BERRY, L. (1985), "A conceptual model of service quality and its implications for future research", Journal of Marketing, 49 (4), 41-50.

PARASURAMAN, A., ZEITHAML, V. e MALHOTRA, A. (2005), "E-S-Qual: A multiple-item scale for assessing electronic service quality", Journal of Service Research, 7 (3), 213-233.

PARASURAMAN, A., ZEITHAML, V., BERRY, L. (1988), "SERVQUAL: A multiple-item scale for measuring consumer perceptions of service quality", Journal of Retailing, 64 (1), 12.

PETERSON, R., BALASUBRAMANIAN, S. e BRONNENBERG, B. (1997), "Exploring the implications of the Internet for consumer marketing", Journal of the Academy of Marketing Science, 25 (4), 329-346.

PORTER, M. (2001), "Strategy and the Internet", Harvard Business Review, 79 (3), 63-78.

REICHHELD, F. e SCHEFTER, P. (2000), "E-Loyalty: your secret weapon on the Web", Harvard Business Review, 78 (4), 105-113.

SIMONS, L. e BOUWMAN, H. (2005), "Multi-channel service design process: challenges and solutions", Journal Electronic Business, 3 (1), 50-67.

SIMONS, L. e BOUWMAN, H. (2006), "Extended QFD: Multi-channel Service Concept Design", Total Quality Management, 17 (8), 1043-1062.

SOUSA, R. (2002a), A qualidade em serviços prestados pela Internet. Managerial Report - Universidade Católica Portuguesa.

SOUSA, R. (2002b), The relationship between quality and loyalty in multichannel e-services. Projecto de Investigação - Universidade Católica do Porto.

SOUSA, R. e AMORIM, M. (2009), "A framework for the design of multichannel services", In Proceedings of the $16^{\text {th }}$ International Annual Conference of the European Operations Management Association, Goteborg, Sweden, 14-17 June 2009 (digital proceedings). 
SOUSA, R. e VOSS, C. (2002), "Quality management re-visited: a reflective review and agenda for future research", Journal of Operations Management, 20 (1), 91-109.

SOUSA, R. e VOSS, C. (2006), "Service quality in multichannel services employing virtual channels", Journal of Service Research, 8 (4), 356-371.

STERN, L., EL-ANSARY, A. e COUGHLAN, A. (1996), Marketing channels. $5^{\text {th }}$ edition. Englewood Cliffs: Prentice Hall.

TEAS, R. (1993), "Expectations, performance evaluation, and consumers' perceptions of quality", Journal of Marketing, 57 (4), 18.

THORNTON, J. e WHITE, L. (2001), "Customer orientations and usage of financial distribution channels", Journal of Service Marketing, 15 (3), 16885.

WOLFINBARGER, M. e GILLY, M. (2003), "ETAILQ: Dimensionalizing, measuring and predicting eTail quality", Journal of retailing, 79 (3), 183193.

WRIGHT, A. (2002), "Technologies as an enabler of the global branding of retail financial services", Journal of International Marketing, 10 (2), 83-98.

YOO, B. e DONTHU, N. (2001), "Developing a Scale to measure the perceived quality of Internet shopping sites (SITEQUAL)", Journal of Electronic Commerce, 2 (1), 31-47.

ZEITHAML, V., PARASURAMAN, A. e MALHOTRA, A. (2002), "Service quality delivery through Web sites: A critical review of extant knowledge", Journal of the Academy of Marketing Science, 20 (4), 362-75. 